Int. J. Electrochem. Sci., 15 (2020) $11191-11202$

International Journal of

ELECTROCHEMICAL

SCIENCE

www.electrochemsci.org

\title{
Effect of Nanosized Silicon Dioxide Additive on Plasma Electrolytic Oxidation Coatings Fabricated on Aluminium
}

\author{
Zhi-quan Huang ${ }^{1}$, Rui-qiang Wang $^{2}$, Heng Zhang ${ }^{3}$, Xiao-jie Shen ${ }^{4}, X u$-zhen Zhang ${ }^{1}$, Yang He ${ }^{5}$, \\ Chen Huang ${ }^{5}$, De-jiu Shen ${ }^{1}$, Da-long Li $i^{6, *}$ \\ ${ }^{1}$ State Key Laboratory of Metastable Materials Science and Technology, College of Materials Science \\ and Engineering, Yanshan University, Qinhuangdao 066004, China \\ ${ }^{2}$ School of Material Science and Engineering, Beijing Institute of Technology, Beijing 100081, China \\ ${ }^{3}$ Zhejiang Geely Automobile Co., Ltd. Ningbo 315800, China \\ ${ }^{4}$ Chongqing Institute of Green and Intelligent Technology, Chinese Academy of Sciences \\ ${ }^{5}$ Jiangsu Pacific Precision Forging Co., Ltd. Taizhou 225300, China \\ ${ }^{6}$ College of Mechanical Engineering, Yanshan University, Qinhuangdao 066004, China \\ *E-mail: lidalong613@163.com
}

doi: $10.20964 / 2020.11 .24$

Received: 8 July 2020 / Accepted: 22 August 2020 / Published: 30 September 2020

Plasma electrolytic oxidation (PEO) of AA1060 aluminium was carried out in aluminate electrolytes to develop corrosion-resistant coatings. Different concentrations $(0,2$ and $4 \mathrm{~g} / \mathrm{L})$ of a $\mathrm{SiO}_{2}$ nanoparticle (n$\mathrm{SiO}_{2}$ ) additive and different treatment times of $15 \mathrm{~min}$ and $30 \mathrm{~min}$ were employed in this investigation. The PEO coatings were characterized by using a scanning electron microscopy (SEM) equipped with energy-dispersive X-ray spectroscopy (EDS), and X-ray diffraction (XRD). The corrosion resistances of each coating was evaluated by electrochemical methods. Results showed that $\mathrm{n}-\mathrm{SiO}_{2}$ hindered the formation of the $\alpha-\mathrm{Al}_{2} \mathrm{O}_{3}$ phase and promoted the generation of the $\gamma-\mathrm{Al}_{2} \mathrm{O}_{3}$ and mullite phases. The addition fo $\mathrm{n}-\mathrm{SiO}_{2}$ in the electrolytes could shorten the breakdown time of PEO, enhance the breakdown voltage, reduce the number of pores in the electrolyte/coating $(\mathrm{E} / \mathrm{C})$ interface and enlarge the internal cavity. The coating formed after $15 \mathrm{~min}$ in a $\mathrm{NaAlO}_{2}$ solution containing $4 \mathrm{~g} / \mathrm{L} \mathrm{n}-\mathrm{SiO}_{2}$ additive showed the best corrosion resistance, exhibiting the lowest corrosion current density of $\sim 8.7 \times 10^{-10} \mathrm{~A} / \mathrm{cm}^{2}$.

Keywords: Nanosilica; Plasma electrolytic oxidation; Pure aluminium

\section{$\underline{\text { FULL TEXT }}$}

(C) 2020 The Authors. Published by ESG (www.electrochemsci.org). This article is an open access article distributed under the terms and conditions of the Creative Commons Attribution license (http://creativecommons.org/licenses/by/4.0/). 